\title{
MITRAL HOMOGRAFTS FOR TOTAL TRICUSPID VALVE REPLACEMENT: COMPARISON OF TWO TECHNIQUES
}

Ulrik Hvass, MD, Frank Baron, MD, Dominique Fourchy, MD, and Yves Pansard, MD, Paris, France

Tricuspid valve dysfunction is generally corrected by annuloplasty or repair. Sometimes, however, the extent of valve damage is beyond the capability of a conservative repair procedure and has to be replaced. ${ }^{1}$ In recent years, mitral homografts $^{2}$ and unstented porcine or pericardial devices ${ }^{3-5}$ have seemed more attractive than mounted valves, especially in cases of active tricuspid endocarditis.

Our retrospective report compares 2 techniques for total tricuspid valve replacement with mitral homografts. Group 1 underwent the technique of Pomar and colleagues, ${ }^{2}$ in which both mitral homograft papillary muscles are secured inside the right ventricle to the tricuspid papillary muscles or to the adjacent inner surface of the right ventricular wall; group 2 underwent a new transmural buttonhole attachment of both homograft papillary muscles.

Patients. Eight operations for total replacement of the tricuspid valve with a mitral homograft have been performed since 1995. Demographics are depicted on Table I.

The first 3 patients (group 1) benefited from the technique previously described by Pomar and colleagues. ${ }^{2}$

The next 5 patients (group 2) were managed by exteriorizing the papillary muscles through 2 buttonholes made in the right ventricular wall. After removal of the diseased tricuspid valve, the mitral homograft is placed in its atrioventricular position. The anterior mitral leaflet is aligned with the recipient's anterior tricuspid anulus and is held in place with a stitch at each fibrous trigone. The mitral papillary muscles are still loose inside the right ventricle and can be viewed through the central mitral opening or behind the anterior mitral leaflet. Any twisting of the chordae will be corrected by adequately rotating the papillary muscles. Basically, each papillary mus-

From the Hôpital Bichat, Chirurgie cardio-vasculare, Paris, France. J Thorac Cardiovasc Surg 2001;121:592-4

Copyright () 2001 by The American Association for Thoracic Surgery

$0022-5223 / 2001 \$ 35.00+0 \quad \mathbf{1 2 / 5 4 / 1 1 0 6 7 8}$

doi: $10.1067 / \mathrm{mtc} .2001 .110678$
Table I. Clinical data of patients undergoing total replacement of the tricuspid valve by using a mitral homograft

\begin{tabular}{cll}
\hline Age $(y)$ & Sex & \multicolumn{1}{c}{ Cause } \\
\hline $\begin{array}{c}\text { Group 1 } \\
35\end{array}$ & M & Porcine valve dysfunction \\
8 & F & Endocarditis (fistula) \\
27 & M & Rheumatic (redo) \\
23 & M & Post-traumatic \\
Group 1 & & \\
33 & M & Rheumatic (redo) \\
25 & M & Carcinoid \\
49 & F & Starr-Edwards valve thrombosis* \\
45 & M & Q fever endocarditis \\
72 & F & Rheumatic \\
\hline
\end{tabular}

*Baxter Healthcare Corp, Edwards Division, Santa Ana, Calif.

cle will be placed through a short 3- to 4-cm opening of the right ventricular wall. The most appropriate site of opening will be selected by placing the body of the papillary muscle against the internal ventricular wall, putting slight tension on the chordae while the leaflets are in their closed position. The anterior papillary muscle will exit from an opening made through the anterior right ventricular wall in the area between the inflow wall and the infundibular wall. The incision will be 2 to $3 \mathrm{~cm}$ away from the atrioventricular groove. The posterior papillary muscle will exit through an opening made in the inferior right ventricular wall in the area between the right ventricular marginal branches and the right posterior descending coronary artery. A couple of stitches will temporarily hold the papillary muscles in position. Sutures for the tricuspid ring are put in place before the mitral leaflets are secured to the tricuspid anulus with a running 3-0 or 4-0 polypropylene suture. A flexible Duran ring, size 29 to 33, will avoid any subsequent annular dilation. Leaflet tension can then be adjusted by mobilizing the papillary muscles from outside the right ven- 

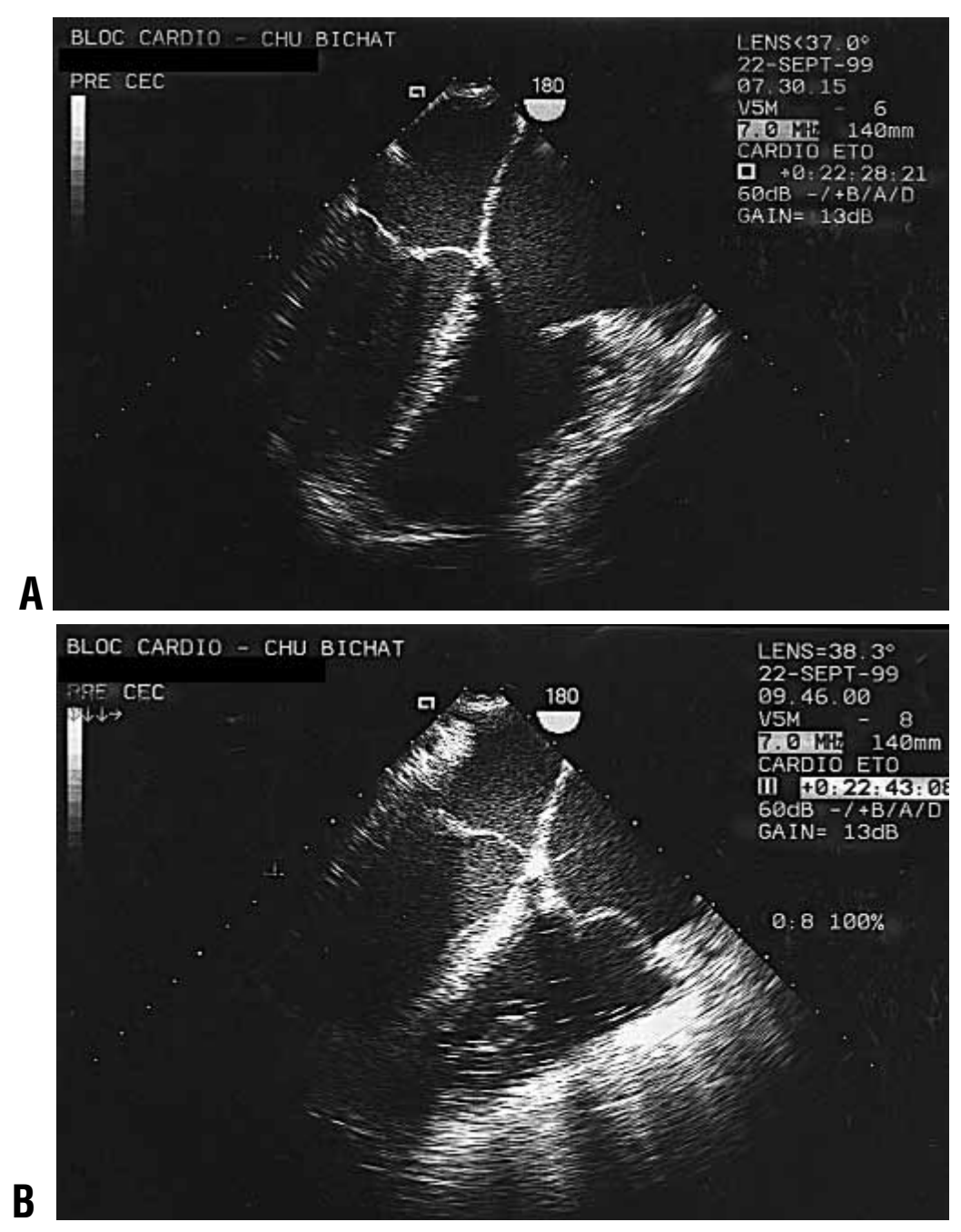

Fig 1. A, Preoperative tricuspid valve in systole. B, Postoperative transesophageal echocardiogram.

tricle. Once an adequate position is found with a nonrestricted motion, and not allowing for any residual prolapse even in the empty and arrested heart, 6 to 12 separate sutures will secure the exteriorized papillary muscles to their respective ventricular wall and ensure hemostasis. Intraoperative offbypass transesophageal echocardiography is mandatory. At this stage of the operation, the tension of the papillary muscle can still be adjusted by removing the stitches, and if leaflet movement is restricted, by letting the papillary muscle slip a bit more into the right ventricular cavity or, more likely, if a residual prolapse is revealed, by further exteriorizing the bulk of the papillary muscle and refixing it in its new position. Readjusting and stabilizing the repair is performed on a beating assisted heart.

Results. All patients survived the operation. Implantation time has been reduced from $105 \pm 37$ minutes in group 1 to $70 \pm 7$ minutes in group 2, reflecting the greater ease of correctly positioning and securing the papillary muscles and consequently in adjusting leaflet and chordal tension.
In group 1, residual prolapse with regurgitation was corrected intraoperatively by repositioning one of the homograft papillary muscles deeper inside the right ventricle in one case and by placing the homograft valvular leaflets above the level of the tricuspid anulus in the other. The final result showed trivial to mild residual leaks.

In group 2, echocardiography (Fig 1) showed no regurgitation, except in the initial case, where one of the papillary muscles was easily repositioned from the outside of the right ventricle to correct residual prolapse, leaving thereafter only a trivial valvular leak.

Echocardiographic follow-up after discharge in both groups shows stable results. No patients were addicted to intravenous drugs. One patient died early after receiving a liver transplant for carcinoid disease 3 months after the tricuspid valve replacement.

Comments. Considering that the valve selection criteria still remain approximate, the greater technical flexibility gained by positioning the mitral homograft papillary muscles 
through the right ventricular wall relieves the surgeon from the constraints of discrepancies that eventually occur between the selected homograft (length of chordae and anatomy and bulk of papillary muscles) and the patient's intraventricular anatomy (size of the right ventricular cavity and location and size of the tricuspid papillary muscles). Compared with our initial experience placing the papillary muscles inside the right ventricle, the buttonhole technique for both anterior and posterior mitral homograft papillary muscles makes the tricuspid valve replacement more predictable and relatively easy to perform.

Received for publication April 26, 2000; accepted for publication July 12, 2000.

Address for reprints: Ulrik Hvass, MD, Hôpital Bichat, Chirurgie cardio-vasculare, rue Henri Huchard, Paris 75018, France.

\section{REFERENCES}

1. Ratnatunga CP, Edwards MB, Dore CJ, Taylor KM. Tricuspid valve replacement: UK Heart Valve Registry mid-term results comparing mechanical and biological prostheses. Ann Thorac Surg 1998;66:1940-7.

2. Pomar JL, Mestres CA, Pare JC, Miro JM. Management of persistent tricuspid endocarditis with transplantation of cryopreserved mitral homografts. J Thorac Cardiovasc Surg 1994;107:1460-3.

3. Frater RWM, Liao K, Seifter E. Stentless chordally supported mitral bioprosthetic valve. New horizons and the future of heart valve bioprostheses. Austin (TX): Silent Partners Inc; 1994. p. 103-19.

4. Walther T, Falk V, Scneider J, Walther C, Morh FW. Stentless tricuspid valve replacement. Ann Thorac Surg 1999;68:1858-60.

5. Vrandecic M, Gontijo FB, Fantini FA, et al. Anatomically complete heterograft mitral valve substitute: surgical technique and immediate results. J Heart Valve Dis 1992;1:253-9. 